\title{
Experimental Investigation on the Durability of Glass Fiber-Reinforced Polymer Composites Containing Nanocomposite
}

\author{
Weiwen Li, ${ }^{1}$ Chunyang Ji, ${ }^{1}$ Honggang Zhu, ${ }^{2}$ Feng Xing, ${ }^{1}$ Jiaxin Wu, ${ }^{1}$ and Xueli Niu ${ }^{1}$ \\ ${ }^{1}$ Shenzhen Durability Center for Civil Engineering, Department of Civil Engineering, Shenzhen University, Shenzhen 518000, China \\ ${ }^{2}$ Nano and Advanced Materials Institute Limited, Hong Kong, China \\ Correspondence should be addressed to Weiwen Li; liweiwen@szu.edu.cn
}

Received 4 May 2013; Accepted 30 September 2013

Academic Editor: Zhi Li Xiao

Copyright (C) 2013 Weiwen Li et al. This is an open access article distributed under the Creative Commons Attribution License, which permits unrestricted use, distribution, and reproduction in any medium, provided the original work is properly cited.

\begin{abstract}
Nanoclay layers incorporated into polymer/clay nanocomposites can inhibit the harmful penetration of water and chemicals into the material, and thus the durability of glass fiber-reinforced polymer (GFRP) composites should be enhanced by using polymer/clay nanocomposite as the matrix material. In this study, $1.5 \mathrm{wt} \%$ vinyl ester (VE)/organoclay and $2 \mathrm{wt} \%$ epoxy (EP)/organoclay nanocomposites were prepared by an in situ polymerization method. The dispersion states of clay in the nanocomposites were studied by performing XRD analysis. GFRP composites were then fabricated with the prepared $1.5 \mathrm{wt} \%$ $\mathrm{VE} /$ clay and $2.0 \mathrm{wt} \% \mathrm{EP} /$ clay nanocomposites to investigate the effects of a nanocomposite matrix on the durability of GFRP composites. The durability of the two kinds of GFRP composites was characterized by monitoring tensile properties following degradation of GFRP specimens aged in water and alkaline solution at $60^{\circ} \mathrm{C}$, and SEM was employed to study fracture behaviors of aged GFRP composites under tension. The results show that tensile properties of the two types of GFRP composites with and without clay degrade significantly with aging time. However, the GFRP composites with nanoclay show a lower degradation rate compared with those without nanoclay, supporting the aforementioned hypothesis. And the modification of EP/GFRP enhanced the durability more effectively.
\end{abstract}

\section{Introduction}

Corrosion of steel reinforcements is one of the major reasons for the degradation of reinforced concrete structures. Various strategies for overcoming this problem have been attempted, such as the employment of cathodic protection and the application of coated and galvanized steel rebar [1]. However, none of these measures have been found to offer significant protection, especially in relatively harsh environments. As such, much effort has been made by researchers worldwide to find a substitute for steel rebar. Over the last three decades, glass fiber-reinforced polymer (GFRP) composites have attracted much attention as possible steel substitutes, due to their high specific strength and modulus and also low cost [2-7]. However, the poor durability of GFRP composites in some harsh environments, especially alkaline environments in which glass fiber is highly susceptible to damage
[8], has hindered the widespread utilization of GFRP as a reinforcing bar in concrete, which is itself alkaline in nature [3]. To improve the attractiveness of GFRP composites for use in the construction industry, measures should be taken to enhance the durability of GFRP composites. Previous studies have shown that degradation of GFRP in alkaline environments is mainly caused by the ingress of water and alkaline ions which leads to matrix material degradation, fiber/matrix interfacial bonding weakening and glass fiber corrosion [3-7]. The durability of GFRP composite in alkaline environments can thus be enhanced by inhibiting the ingress of water and alkaline ions.

Polymer/clay nanocomposites, made by dispersing nanoclay in a polymer matrix, have been under development over the last three decades. Numerous studies have demonstrated that polymer/clay nanocomposites exhibit markedly improved barrier properties against solvents, moisture, 
chemicals, and gases, compared to neat polymers [9]. Thus, one potential direction for enhancing the durability of GFRP composites in alkaline environments is to use polymer/clay nanocomposite as the matrix material of GFRP, taking advantage of its enhanced barrier protection properties. A number of researchers have studied the fabrication and properties of polymer/clay nanocomposite-based GFRP over the last decade [10-13]. Though some interesting findings have been reported for GFRP composites containing nanoclay, there is still a long way to go to fully understand this new composite.

In this study, $1.5 \mathrm{wt} \%$ vinyl ester (VE)/clay and epoxy (EP)/clay nanocomposites were prepared by an in situ polymerization method and the dispersion state was characterized by XRD. In addition, GFRP composites were fabricated with the prepared $1.5 \mathrm{wt} \% \mathrm{VE} /$ clay and $2 \mathrm{wt} \% \mathrm{EP} /$ clay nanocomposites to investigate the effect of clay addition on the durability of GFRP composites. To characterize the durability of the prepared GFRP composites, two kinds of GFRP specimens-with and without nanoclay-were conditioned under two different accelerated aging conditions, namely, immersion in water at $60^{\circ} \mathrm{C}$ and in alkaline solution at $60^{\circ} \mathrm{C}$; the samples were then tested in tension after a predetermined period. SEM was also employed to observe the fracture behavior of tested GFRP specimens.

\section{Materials and Methods}

2.1. Materials. The matrix material used for VE/clay nanocomposite preparation was a bisphenol-A vinyl ester resin (V411, Jinan Yisheng Resin Company, China). Its viscosity, gelation time, and solid content are 0.3-0.6 Pa.s, 6-12 min, and 63-68\%, respectively. The accelerator and initiator employed for VE resin curing were cobalt isooctanoate and methyl ethyl ketone peroxide (Jinan Yisheng Resin Company, China). The epoxy resin was made up of 500A-307 (hard epoxy crystal resin, Boluoxian Composite Materials Limited Company) and 500B-307 (curing agent, Boluoxian Composite Materials Limited Company) in the mass ratio of $3: 1$. At $25^{\circ} \mathrm{C}$, the viscosities of the two resin components are 1200$1600 \mathrm{cps}$ (500A-307) and 8-12 cps (500B-307); the specific densities are $1.07 \mathrm{~g} / \mathrm{cm}^{3}$ (500A-307) and $0.93 \mathrm{~g} / \mathrm{cm}^{3}$ (500B307). The clay used was I.30P organoclay (Nanocor, Inc.), which is montmorillonite modified with $33 \mathrm{wt} \%$ primary octadecylamine. The glass fiber used for GFRP composite fabrication was a unidirectional alkali-free E-glass fabric supplied by Haining Wanwei Textile Co., Ltd. Its density, thickness, strength, elastic modulus, and failure strain of a single fiber under tension are $300 \mathrm{~g} / \mathrm{m}^{2}, 0.2 \mathrm{~mm}, 3.1 \mathrm{GPa}$, $73 \mathrm{GPa}$, and $3.8 \%$, respectively.

\subsection{Preparation and Characterization of VE/MMT Nanocom-} posite. In this study, an in situ polymerization method was used for VE/clay nanocomposite preparation. The required amount of I.30P organoclay, which had been dried at $80^{\circ} \mathrm{C}$ for 12 hours, was first added to the required amount of styrene and stirred manually, followed by $1 \mathrm{~h}$ ultrasonication at room temperature. The styrene/clay mixture was then blended with the required amount of VE resin. The obtained mixture was then shear mixed at $3500 \mathrm{rpm}$ for $2 \mathrm{~h}$ and then further ultrasonicated for $30 \mathrm{~min}$. After degassing for $15 \mathrm{~min}$, accelerator and initiator were added into the clay/VE mixture in a mass ratio of $1 \%$ and $2 \%$, respectively, under slow stirring. The VE/clay mixture was then ready for use in nanocomposite specimens and GFRP composite preparation.

The EP/clay nanocomposites were also fabricated by in situ polymerization. After the I.30P organoclay was dried at $80^{\circ} \mathrm{C}$ for 10 hours and the epoxy resin at $100^{\circ} \mathrm{C}$ for 10 minutes, the organoclay and resin were shear mixed at $3100 \mathrm{rpm}$ for $1 \mathrm{~h}$ and then ultrasonicated for a further $2 \mathrm{~h}$. After degassing for $2 \mathrm{~h}$, curing agent was added to the EP/clay mixture in the mass ratio $3: 1$.

The dispersion state of the clay in the prepared VE/clay and EP/clay nanocomposites was characterized by measuring the interlayer spacing of clay on an X-ray diffract meter (XRD, Bruker AXS Gmbh, D8 ADVANCE), which is equipped with a $\mathrm{Cu}$ Ka radiation $(1.254 \mathrm{~nm})$ source. The diffraction spectra were obtained at room temperature at a scanning rate of $0.1 / \mathrm{min}$ from $2^{\circ}$ to $10^{\circ}$. The spacing between the diffraction lattice planes, $d$, was calculated using Bragg's law:

$$
n \lambda=2 d \sin \theta,
$$

where $\theta$ is the diffraction angle (in degree) and $\lambda$ is the wavelength of the incident ray.

\subsection{Preparation and Characterization of GFRP Composites} with and without Nanoclay. In this study, GFRP composites without nanoclay were fabricated from neat VE resin and neat EP, while GFRP composites with nanoclay were fabricated with $1.5 \mathrm{wt} \% \mathrm{VE} /$ clay and $2 \mathrm{wt} \% \mathrm{EP} /$ clay nanocomposite. Laminate specimens, $275 \mathrm{~mm}$ long, $160 \mathrm{~mm}$ wide, and $2 \mathrm{~mm}$ thick, were prepared for both kinds of GFRP composites using the hand lay-up method. Right before the preparation of laminates, appropriate amounts of accelerator and initiator were added into neat $\mathrm{VE}$ resin or $1.5 \mathrm{wt} \% \mathrm{VE} /$ clay mixture with gentle stirring, until the mixture became homogeneous. The curing agent was also added into the EP resin with gentle stirring. The preparation process was the same for both the $\mathrm{VE} /$ clay nanocomposites and the EP/clay nanocomposites. One layer of matrix material was poured into a specially designed Teflon mould. Layers of glass fabric were then stacked in the mould with the same fiber orientation and with the matrix resin applied in between until the desired number of plies laid. Following the application of the final layer of matrix material, the uncured GFRP laminate was covered by the mould cover. Prior to any conditioning or testing, the prepared GFRP laminates were cured at $100^{\circ} \mathrm{C}$ for $2 \mathrm{~h}$ followed by 10 days of further curing at room temperature. The content of glass fiber in the prepared GFRP laminates was measured to be 60 vol\% by ignition.

To study the tensile properties of GFRP composite with and without nanoclay, tensile specimens, $250 \mathrm{~mm}$ long, $24 \mathrm{~mm}$ wide, and $2 \mathrm{~mm}$ thick, were cut from the prepared GFRP laminates. Similar to tensile specimens of VE/clay nanocomposites, aluminum bevel $\left(8^{\circ}-10^{\circ}\right)$ tabs, $60 \mathrm{~mm}$ long, $24 \mathrm{~mm}$ wide, and $2 \mathrm{~mm}$ thick, were attached to both ends of the GFRP tensile specimens (as shown in Figure 1). 

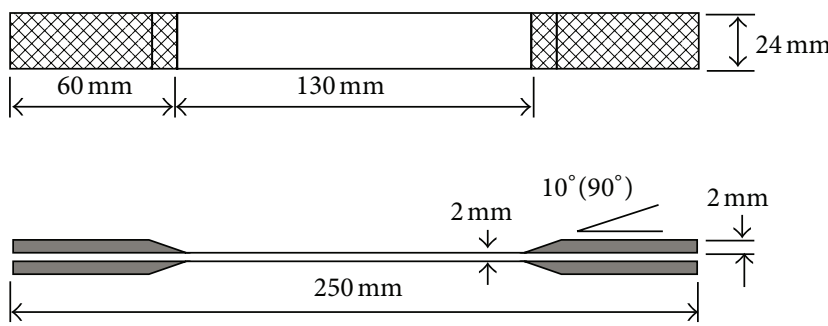

FIgURE 1: The pattern of tensile specimen.

Three specimens were prepared and tested for each case. The tensile test was performed at room temperature with a pace rate of $2.5 \mathrm{~mm} / \mathrm{min}$ following the specifications in ASTM D3039 [14] using a universal testing machine (RGM4100). An extensometer with a gauge length of $50 \mathrm{~mm}$ was also employed for elongation measurements. The tensile strength, elastic modulus, and failure strain of each specimen were determined following the principles described in Section 2.2. The fracture surfaces of tested tensile specimens were observed with SEM.

2.4. Durability Study of GFRP Composites with and without Clay. In this study, the durability of GFRP composites (including VE/clay nanocomposite GFRP and EP/clay nanocomposite) was investigated, with and without nanoclay and in both humid and alkaline environments. To characterize the durability of GFRP composites, both kinds of GFRP laminates were immersed in both deionized water and in alkaline solution, at $60^{\circ} \mathrm{C}$, for predetermined periods. A temperature somewhat above room temperature was chosen in order to accelerate the degradation of the GFRP composites. The alkaline solution employed consisted of deionized water, $\mathrm{KOH}, \mathrm{NaOH}$, and $\mathrm{Ca}(\mathrm{OH})_{2}$ in the mass ratio $1: 0.014: 0.01: 0.0016$, and its $\mathrm{pH}$ value was around 13 . The aging of the samples was analyzed after time intervals of 0 , $15,30,45$, and 60 days.

After each predetermined period, four GFRP laminates (two with clay and two without clay) were removed from the water and alkaline solutions. Then five specimens, $250 \mathrm{~mm}$ long, $24 \mathrm{~mm}$ wide, and $2 \mathrm{~mm}$ thick, were cut from each GFRP laminate following the pattern shown in Figure 2. However, taking edge effects into consideration, only three central specimens (marked as A, B, and C) were used for testing the tensile properties of the aged GFRP composites. The tensile tests were conducted following the procedures specified in Section 2.3. SEM was also employed to observe the fracture surfaces of the aged GFRP specimens.

\section{Results and Discussions}

3.1. Dispersion States of the VE/Clay and EP/Clay Nanocomposites. The XRD spectra of neat montmorillonite powder and $\mathrm{VE} /$ clay nanocomposite, as well as neat montmorillonite powder and EP/clay nanocomposite, are shown in Figures 3 and 4, respectively. The results are diffraction-limited to angles greater than $2.7^{\circ}$. The reflection peak of the neat
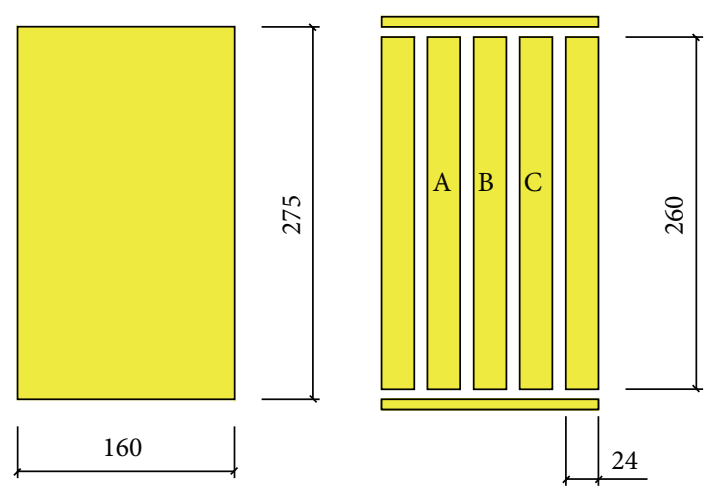

FIGURE 2: The cutting pattern of the accelerated deterioration test specimens.

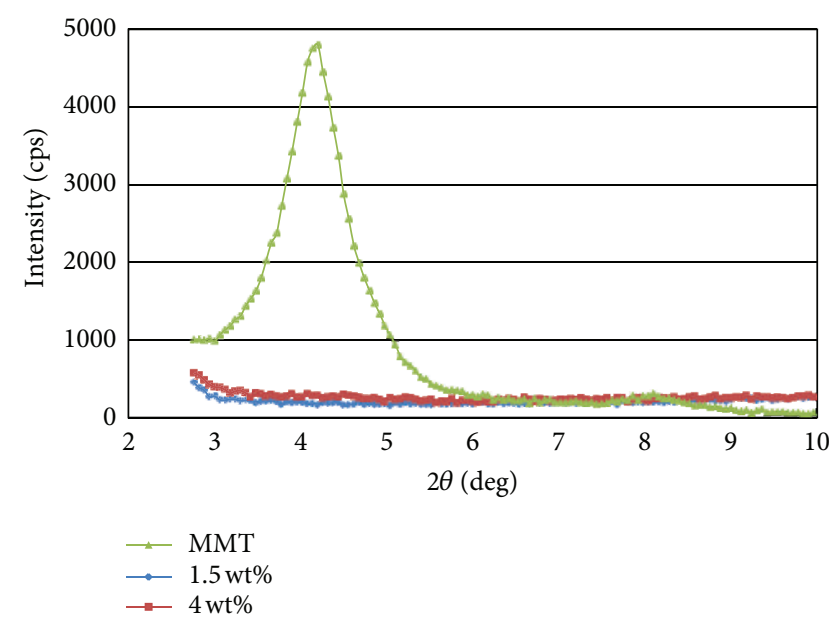

FIGURE 3: XRD spectra of neat montmorillonite powder and $1.5 \mathrm{wt} \%$, $4 \mathrm{wt} \% \mathrm{VE} /$ clay nanocomposite.

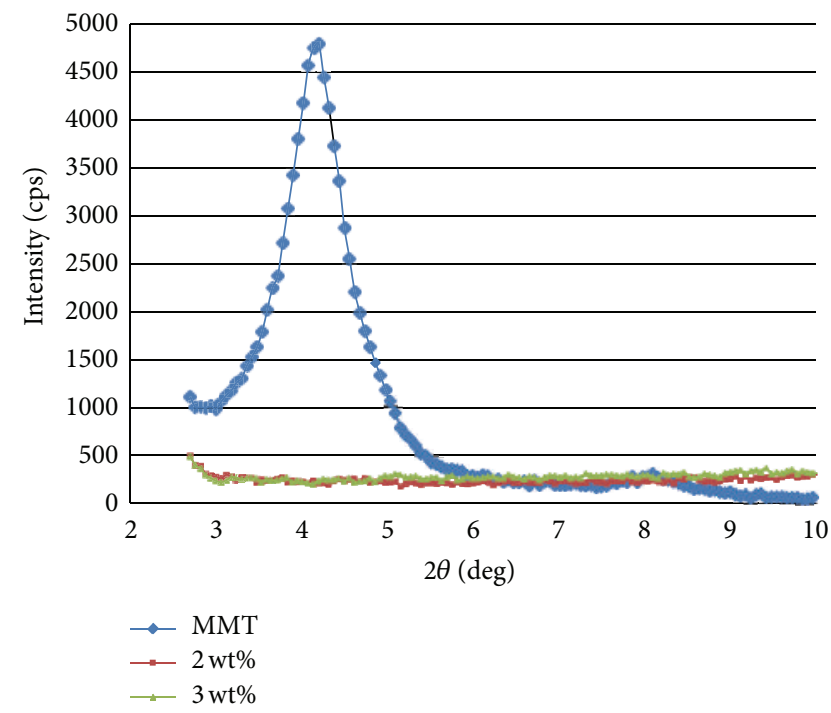

FIGURE 4: XRD spectra of neat montmorillonite powder and $2 \mathrm{wt} \%$, $3 \mathrm{wt} \% \mathrm{EP} /$ clay nanocomposite. 
TABLE 1: Tensile strength and elastic modulus of control GFRP composites with and without clay.

\begin{tabular}{|c|c|c|c|c|}
\hline & Tensile strength $(\mathrm{MPa})$ & Average strength $(\mathrm{MPa})$ & Elastic modulus (GPa) & Average modulus (GPa) \\
\hline \multirow{3}{*}{ VE-GFRP } & 426.16 & & 26.29 & \multirow{3}{*}{27.31} \\
\hline & 414.64 & 417.98 & 28.51 & \\
\hline & 413.15 & & 27.13 & \\
\hline \multirow{3}{*}{ VE/clay nano-GFRP } & 483.32 & & 27.35 & \multirow{3}{*}{28.18} \\
\hline & 444.38 & 467.25 & 28.25 & \\
\hline & 474.06 & & 28.93 & \\
\hline
\end{tabular}

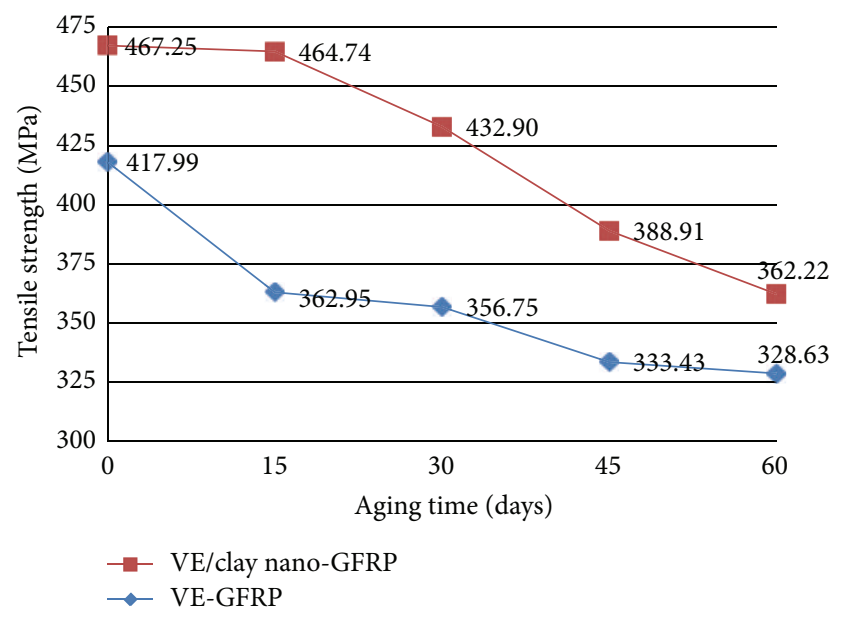

FIGURE 5: Tensile strength of GFRP after deterioration in water.

montmorillonite appears at $2 \theta \approx 4.1^{\circ}$ in Figures 3 and 4 , and the corresponding interlayer spacing calculated from Bragg's law is $2.15 \mathrm{~nm}$. The reflection peaks of the VE/clay and EP/clay nanocomposites with different montmorillonite content completely disappear from the spectra; this implies that the interlayer spacing increased to above $3.23 \mathrm{~nm}$ (corresponding to $2 \theta<2.7^{\circ}$ ). The increased spacing may be due to polymer molecules becoming intercalated into the interlayer space, or even to exfoliation of some of the clay [13].

3.2. Properties of VE-GFRPs and VE/Clay Nano-GFRPs. The experimental results shown in Table 1 refer to the specimens which were not subjected to deterioration tests. For the VEGFRPs (GFRP composites containing neat vinyl eater resin), the average tensile strength was found to be $467.42 \mathrm{MPa}$ and the average elastic modulus was $27.31 \mathrm{GPa}$. For the VE/clay nano-GFRPs, the mean tensile strength was $417.98 \mathrm{MPa}$ and the average elastic modulus was $28.18 \mathrm{GPa}$. The enhancement of the average tensile strength on addition of montmorillonite was $11.83 \%$ and that of the average elastic modulus was $3.2 \%$.

For the specimens immersed in water, the tensile strength and elastic modulus of both the VE-GFRP and the VE/clay nano-GFRP decreased with time (Figures 4 and 5). As Figure 5 shows, the tensile strength of the VE-GFRP decreased by about $13.17 \%$ after 15 days; in contrast, the tensile strength of the VE/clay nano-GFRP decreased by only $0.54 \%$ over the same time period. However, after 30 days the tensile properties of the VE/clay nano-GFRP began to decrease significantly. As Figure 6 illustrates, the elastic modulus also

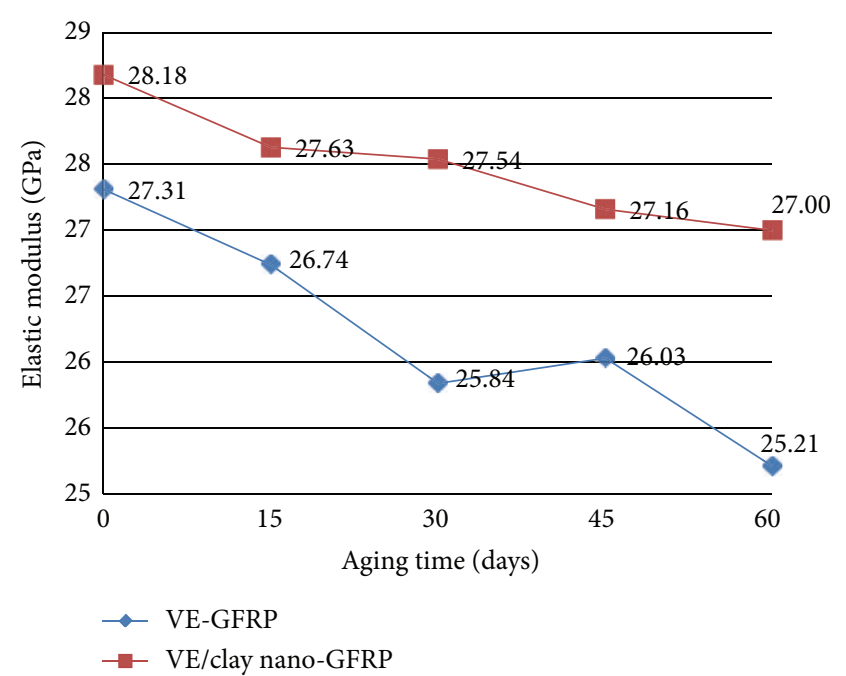

FIGURE 6: Elastic modulus of GFRP after deterioration in water.

decreased over time, but much more gradually; the elastic modulus for VE-GFRP and VE/clay nano-GFRP reduced by $7.69 \%$ and $4.19 \%$, respectively, after 60 days, at a fairly steady rate.

As Figure 7 shows, the reductions in the tensile strengths of VE-GFRP and VE/clay nano-GFRP for the samples soaked in the alkaline solution were more obvious than for those in water. The final reduction in the tensile strength of the VE/clay nano-GFRP (47.91\% after 60 days) was less than that for the VE-GFRP (57.24\%). Compared with the reduction in the tensile strength, the decrease in the elastic modulus was less pronounced; as shown in Figure 8, the reductions in the elastic moduli for VE-GFRP and VE/clay nano-GFRP after 60 days in alkaline solution were $17.65 \%$ and $11.75 \%$, respectively.

The above experimental results demonstrate that the durability of the GFRPs is inferior when immersed in the alkali solution compared to immersion in water. The corrosion mechanism in an alkaline environment involves alkaline ions using water as a carrier to permeate deep into the matrix material, where they act to decrease the tensile strength by damaging the matrix materials, glass fibers, and the matrixfiber interfaces. Hence, the influence of corrosion caused by an alkaline solution can be treated as a superposition of water-induced corrosion and the alkaline ion-induced corrosion, as the following equation indicates:

$$
c=a+b \text {. }
$$




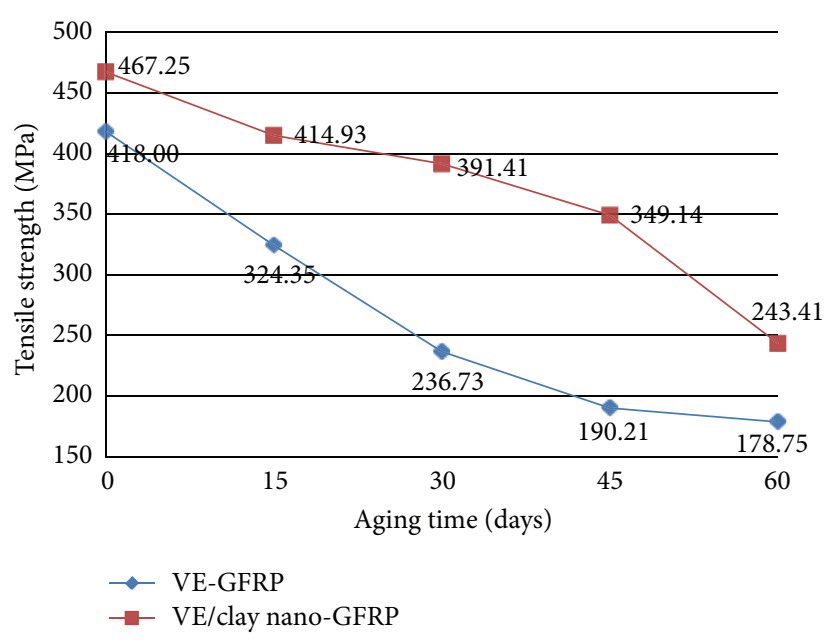

FIgURE 7: Tensile strength of GFRP after deterioration in alkaline solution.

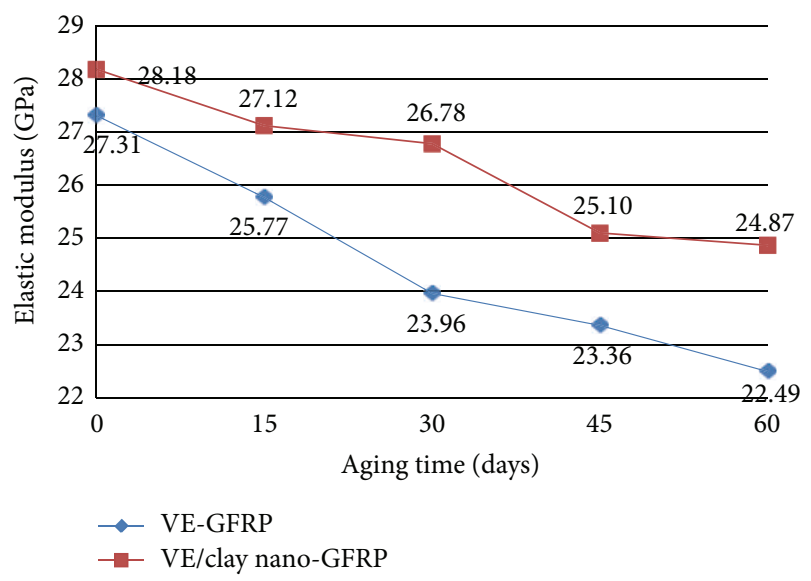

FIGURE 8: Elastic modulus of GFRP after deterioration in alkaline solution.

In this equation, $c$ is the effect of the total corrosion in alkaline solution, $a$ is the effect of water-induced corrosion, and $b$ is the effect of alkaline ion-induced corrosion.

Figures 9 and 10 can be explained by this equation. $c$, the vertical distance from the black line to the blue line, can be interpreted as the sum of $a$ and $b$, where $a$ represents the reduction caused by water (black line to red line) and $b$ represents the reduction purely due to the alkaline ions (red line to blue line).

Figure 9 shows that $b$ (the effect of alkaline ions) exceeds $a$ (the effect of the water) after 30 days. The corrosion is then dominated by the alkaline ions; by this stage, the alkaline ions have permeated into the specimens with the water and interacted with the glass fibers and matrix materials, leading to reductions in the tensile strength of the VE-GFRP. The corrosion caused by the alkaline ions becomes worse over time, as demonstrated by the steady increase of $b$ with time. This shows that the VE matrix cannot ultimately resist the permeation of alkaline ions, and they can damage the matrixfiber interface and interact with the glass fibers and matrix

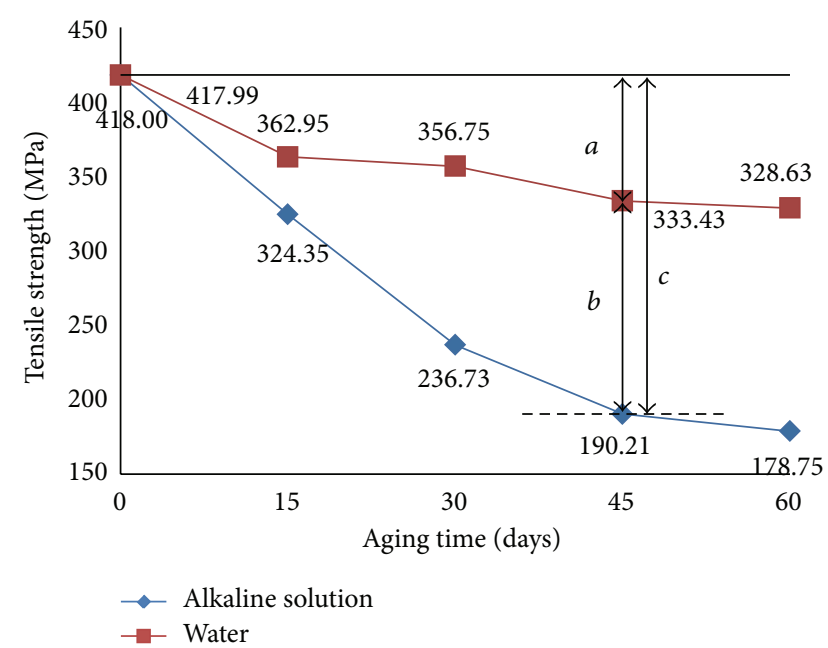

FIGURE 9: The tensile strength of VE-GFRP in deterioration environment.

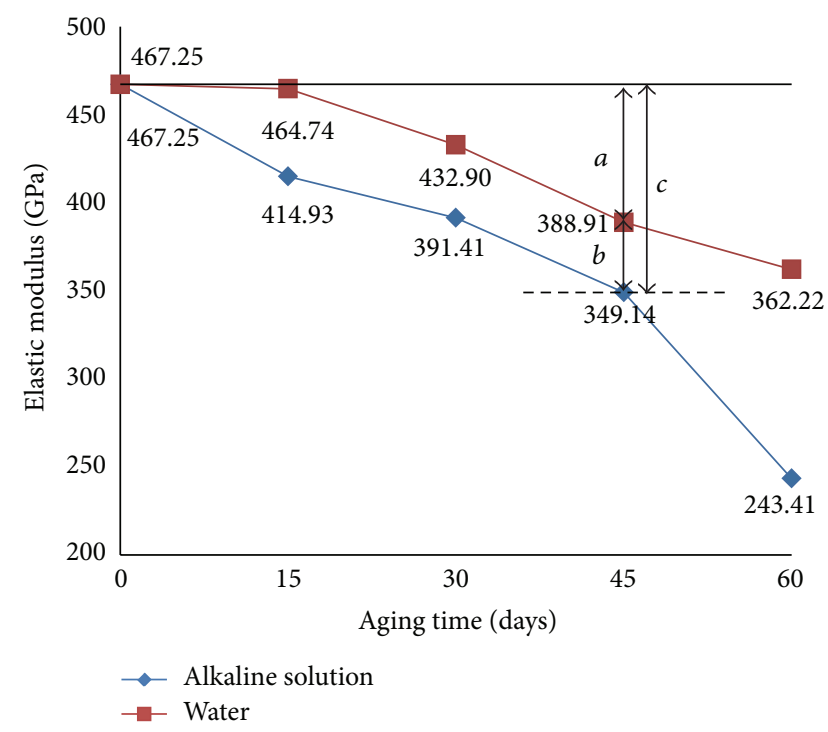

FIGURE 10: The elastic modulus of VE/clay nano-GFRP in deterioration environment.

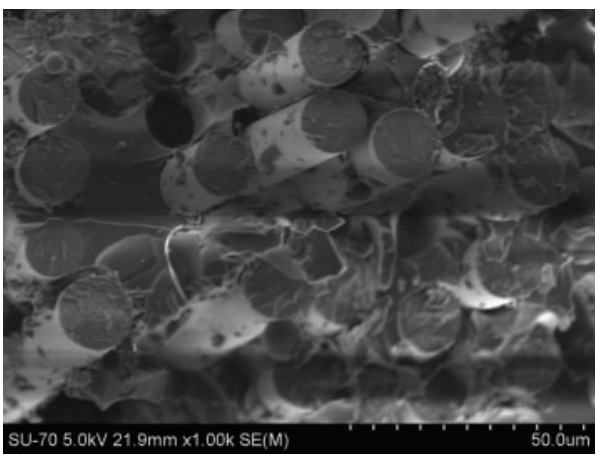

FIgURE 11: The SEM images of cross-section of fracture surface of VE-GFRP. 


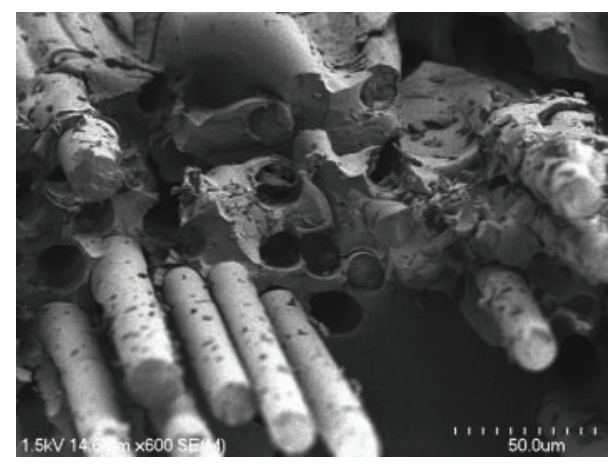

FIGURE 12: The SEM images of fracture surface of VE-GFRP immersed in water for 45 days.

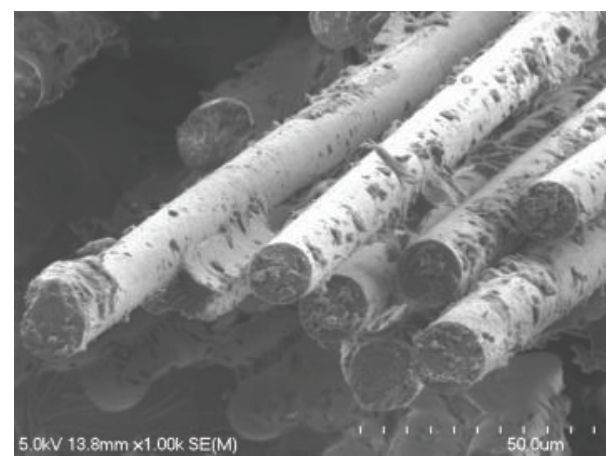

FIGURE 13: The SEM images of fracture surface of VE-GFRP immersed in alkaline solution for 45 days.

materials to decrease the tensile strength after only a relatively short time.

In contrast, Figure 10 shows that for the VE/clay nanoGFRP $b$ is less pronounced before 45 days. This means that corrosion is dominated by water and the alkaline ions have not significantly permeated into the matrix. After 45 days, $b$ increases suddenly and continues to do so over time; corrosion becomes dominated by the alkaline ions. The reason is that the addition of montmorillonite can restrict the permeation of the alkaline ions and decrease the corrosion of glass fiber at early times. It protects the inner glass fibers and improves the durability effectively.

The fracture surfaces and glass fibers were examined by SEM. As illustrated in Figures 11, 12, and 13, the matrix presents a typical brittle failure and the pullout of the glass fiber indicates that the failure of the VE-GFRP is the result of fiber pullout rather than the failure of the fibers themselves. This indicates that the glass fibers do not take up their potential maximum load before the failure of the VE-GFRP and that matrix-fiber interface bonding is the weak point.

Comparing Figures 11 and 14, Figures 12 and 15, and Figures 13 and 16, respectively, it is found that the fracture surfaces of the VE/clay nano-GFRP are relatively coarser. The observation of squama texture and some tiny fragments around the glass fibers could lend strength to the view that the ductility of the VE/clay nano-GFRP has been improved. The fact that glass fiber pullout is seldom observed and the evenness of the fracture surface both indicate that

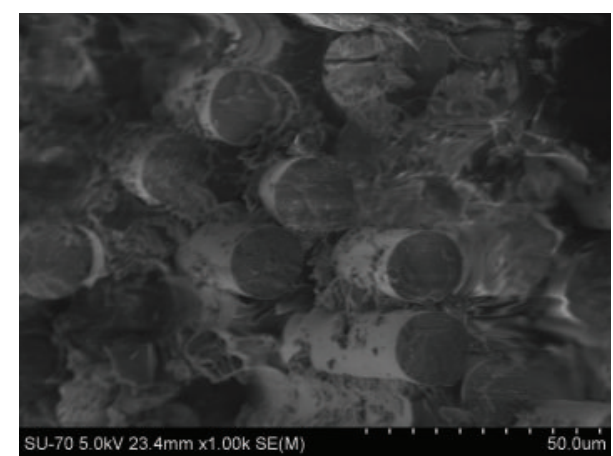

FIGURE 14: The SEM images of cross-section fracture surface of VE/ clay nano-GFRP.

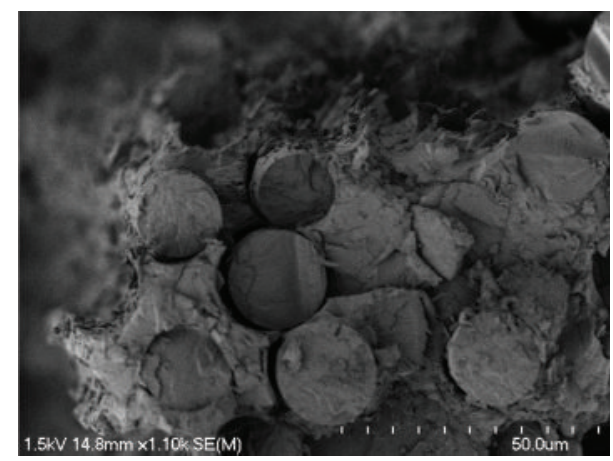

FIGURE 15: The SEM images of fracture surface of VE/clay nanoGFRP immersed in water for 45 days.

the interfacial bonding between the fiber and the matrix is increased relative to VE-GFRP. The silicate layers play a role in developing connections among the glass fibers, or between the glass fibers and the matrix. So the transmissions of tension and shear force occur through the bridges built by the silicate layers of the montmorillonite.

A longitudinal section of fiber fracture for VE-GFRP is shown in Figure 17. Most of the fibers are seen to have exfoliated from the matrix, while the glass fibers kept a relatively complete shape. This demonstrates that the matrixfiber interfacial bonding is poor. There were essentially no tiny fragments left on the surface of the glass fibers, and this indicates that the common vinyl ester matrix is brittle. The longitudinal section of fiber fracture for VE/clay nanoGFRP is shown in Figure 18. In contrast to the fracture surface of the VE-GFRP, the fracture surface of the VE/clay nanoGFRP presents a squama texture and a large number of tiny fragments adhered to the surface of the glass fibers. After the failure of VE/clay nano-GFRP, the glass fibers are still embedded in the matrix. Most of the glass fibers are found to have broken. Less exfoliation of the fibers is observed. All of the above characteristics of the VE/clay nano-GFRP support the idea that the ductility and fiber-matrix interfacial bonding is improved after addition of montmorillonite.

3.3. Properties of EP-GFRPs and EP/Clay Nano-GFRPs. Figures 19 and 20 show the mechanical properties of EP-GFRP 


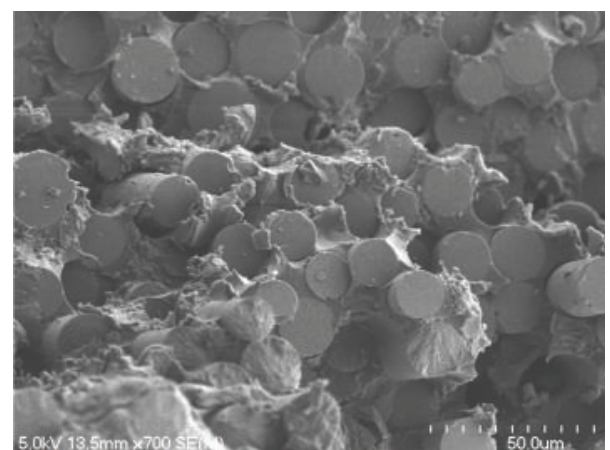

FIGURE 16: The SEM images of fracture surface of VE/clay nanoGFRP immersed in alkaline solution for 45 days.

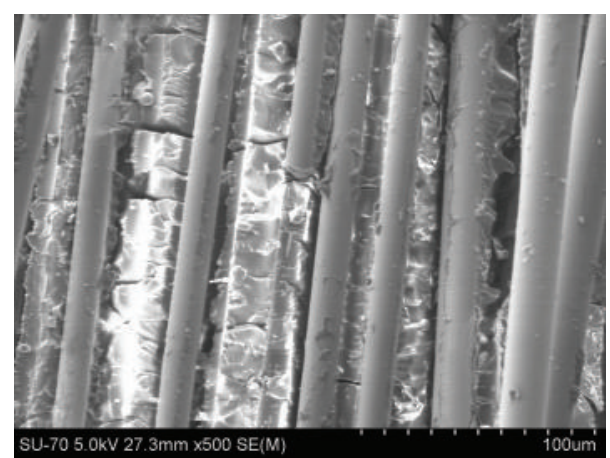

FIGURE 17: The SEM images of longitudinal section of fiber fracture of VE-GFRP.

(GFRP composites containing neat epoxy resin) and EP/clay nano-GFRP after immersion in water at $60^{\circ} \mathrm{C}$. For both the tensile strength and elastic modulus, the overall trend is a decrease over time, and the decrease for the EP-GFRP is more significant than that for the EP/clay nano-GFRP. After 60 days, the reductions in tensile strengths were $18.75 \%$ and $12.36 \%$ for the EP-GFRP and EP/clay GFRP, respectively. The elastic moduli of the EP-GFRP and EP/clay nano-GFRP were decreased by $10.16 \%$ and $4.39 \%$, respectively. Before the 30 day mark, the reduction rates of the tensile strength for EPGFRP and EP/clay nano-GFRP were similar, but after 30 days, the tensile strength of the EP-GFRP dropped at a significantly faster rate than that of the EP/clay nano-GFRP. This indicates that the mechanical properties of the EP/clay nano-GFRP are superior to those of the EP-GFRP.

The following results focus on the mechanical prosperities of the GFRPs immersed in alkaline solution at $60^{\circ} \mathrm{C}$. The tensile strength of EP-GFRP was decreased by $38.41 \%$ after 60 days, which is substantially higher than the reduction for EP/clay nano-GFRP, at 32.03\% (Figure 21). Before 30, days the rate of decrease for the EP/clay nano-GFRP was slower than for EP-GFRP. This indicates that at early times during the accelerated aging test, the addition of the montmorillonite enhanced the mechanical properties of GFRP and effectively prevented the permeation of water and chemicals. As Figure 22 shows, the elastic moduli of EP-GFRP and EP/clay nano-GFRP both decreased over time. After 60 days,

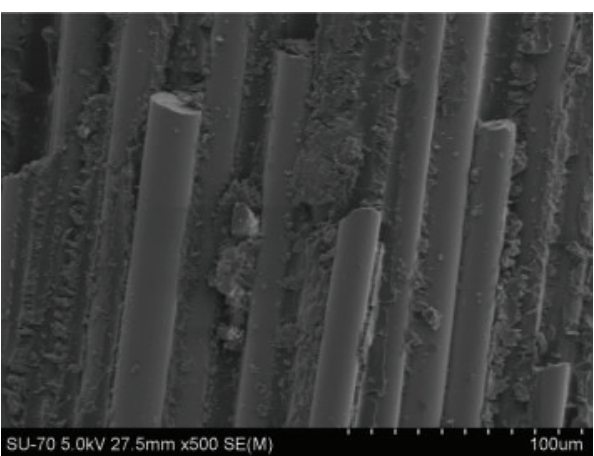

FIGURE 18: The SEM images of longitudinal section of fiber fracture of VE/clay nano-GFRP.

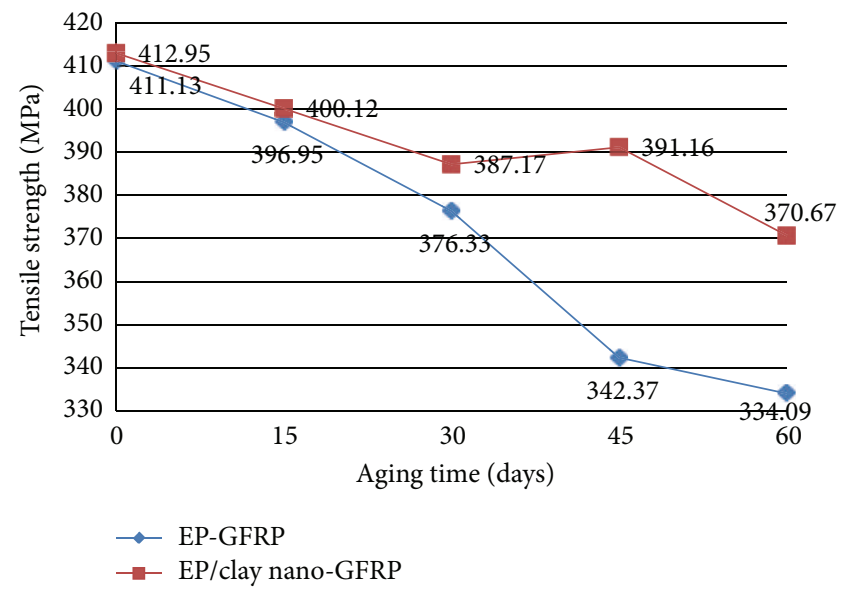

FIGURE 19: Tensile strength of EP-GFRP after deterioration in water.

the elastic modulus of EP-GFRP and EP/clay nano-GFRP decreased by $20.52 \%$ and $21.75 \%$, respectively. The mechanical properties of EP-GFRP are found to be consistently inferior to those of EP/clay nano-GFRP.

Similar to the previous section, the influences of water and alkaline ions on degradation were studied and compared with the equation $c=a+b$. Figure 23 shows the tensile strength of EP-GFRP immersed in water and alkaline solution at $60^{\circ} \mathrm{C}$. The contributions of the water and the alkaline solution to the overall corrosion grow at approximately the same rate. Over the whole duration of the accelerated aging test, the alkaline ion corrosion is greater than the water corrosion. This indicates that the alkaline ions are the dominant cause of degradation of the mechanical properties of EP-GFRP, which cannot adequately resist the permeations of alkaline ions. These experimental results are consistent with the known conclusion that alkaline ions have a strong influence on the degradation of GFRPs.

Figure 24 plots the tensile strength of EP/clay nanoGFRP immersed in water and alkaline solution. In contrast to Figure 23, the contribution of alkaline ions to the corrosion is less than that of water during the early stages of the accelerated aging test. This suggests that the addition of montmorillonite leads to the formation of barriers that resist the permeation of chemicals such as 


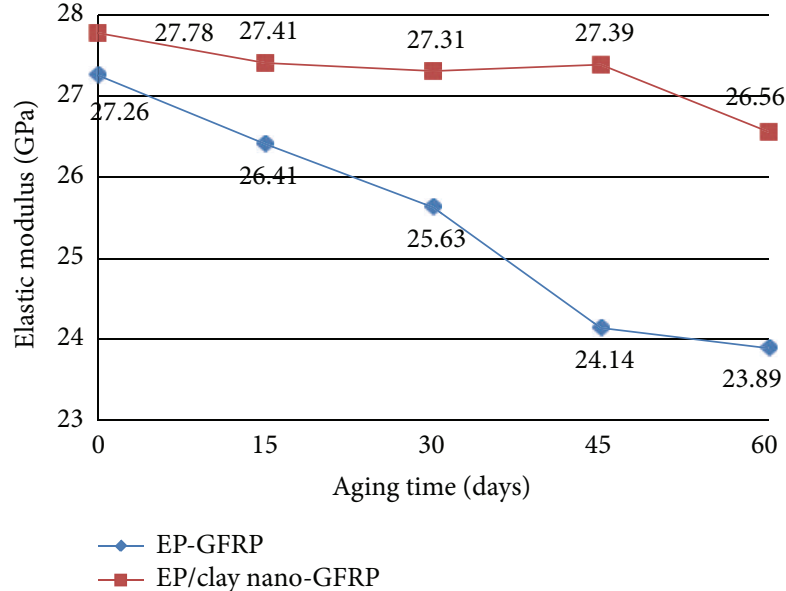

FIGURE 20: Elastic modulus of EP-GFRP after deterioration in water.

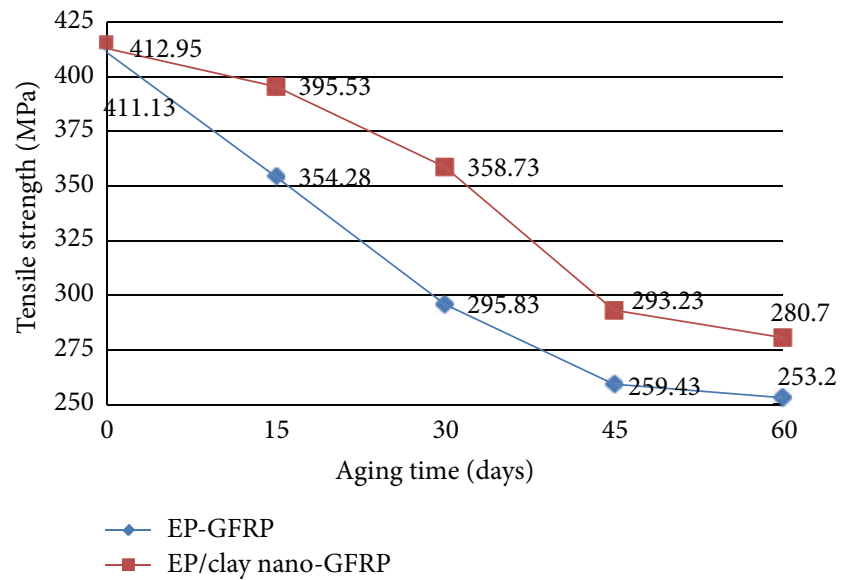

FIGURE 21: Tensile strength of EP-GFRP after deterioration in alkaline solution.

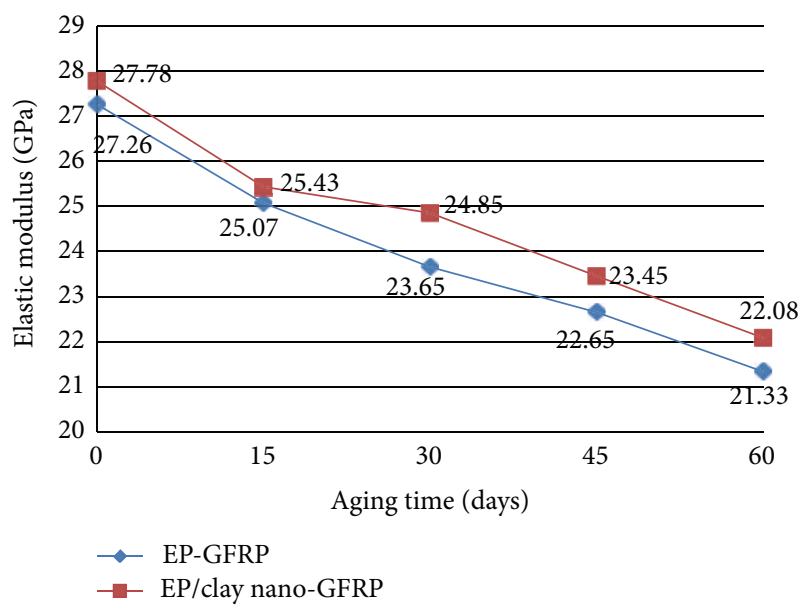

FIGURE 22: Elastic modulus of EP-GFRP after deterioration in alkaline solution.

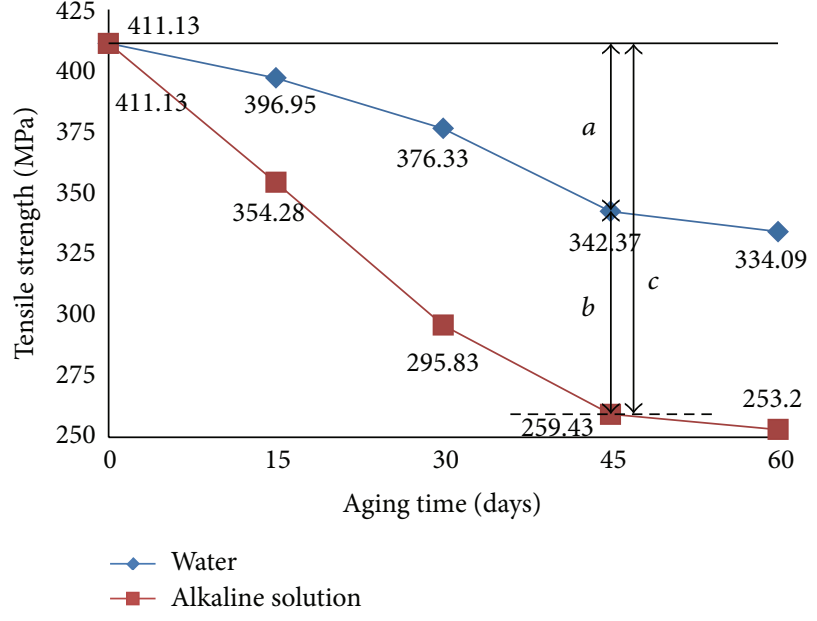

FIgURE 23: The tensile strength of EP-GFRP in deterioration environment.

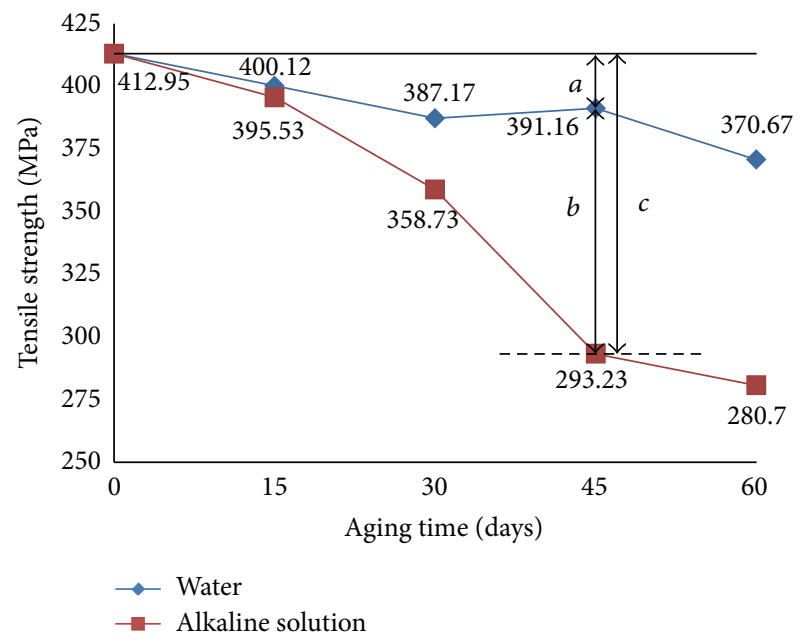

FIGURE 24: The tensile strength of EP/clay nano-GFRP in deterioration environment.

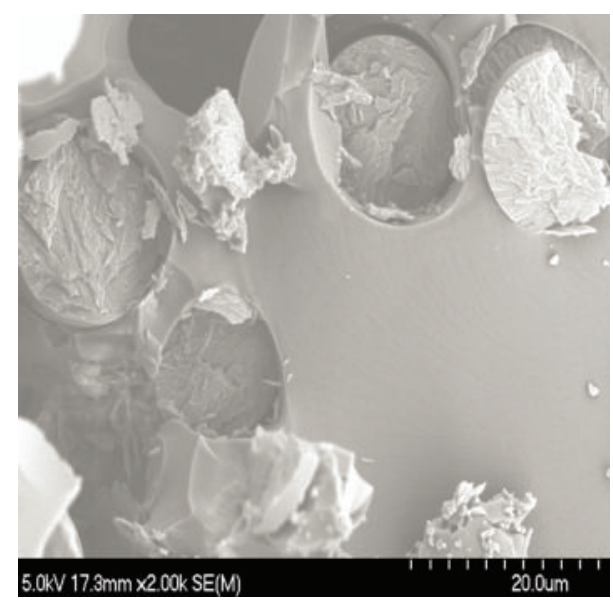

FIGURE 25: The SEM images of cross-section of fracture surface of EP-GFRP. 


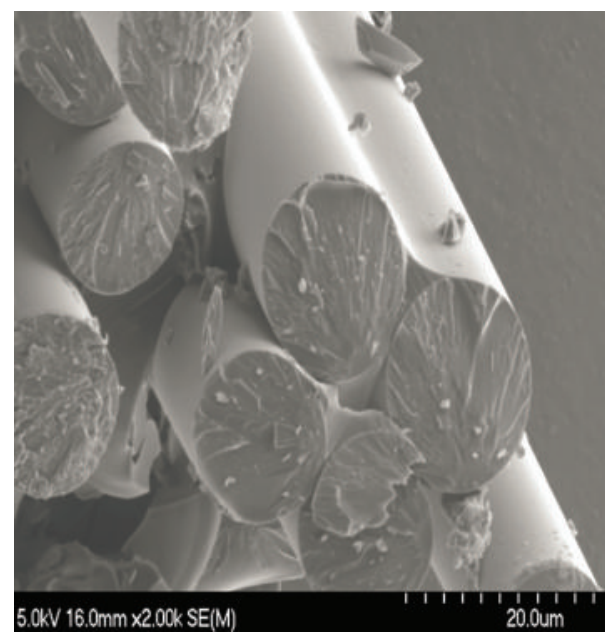

FIGURE 26: The SEM images of cross-section fracture surface of EP/ clay nano-GFRP.

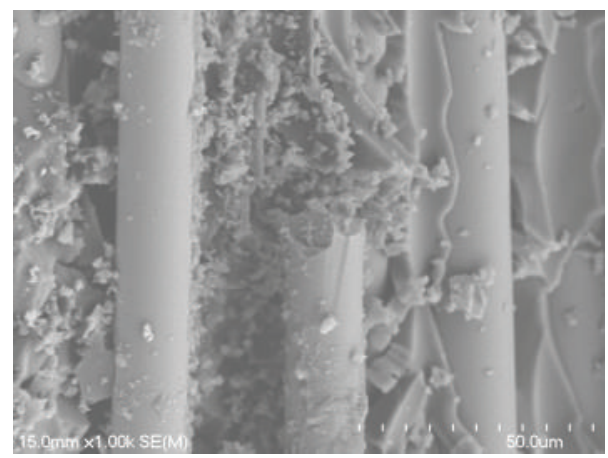

FIGURE 27: The SEM images of longitudinal section of fiber fracture of EP-GFRP.

alkaline ions; degradation of the mechanical properties of the EP/clay nano-GFRP is thus delayed by the protection provided by the EP/clay nanocomposites to the fibers. After 30 days, the relative contribution of the alkaline ions to corrosion is seen to increase substantially, indicating that the alkaline ions do eventually permeate into the matrix and then interact with the matrix materials, disrupting the matrixfiber interfacial bonding or even damaging the fibers. At later times, the mechanical degradation of EP/clay nano-GFRP is dominated by the alkaline ions. The critical time at which alkaline ions become the major factor in the degradation of the mechanical properties is delayed, which could explain the overall increase in durability associated with the addition of montmorillonite.

Figures 25 and 26 show the fracture surface of fiber embedded in EP-GFRP and EP/clay nano-GFRP, respectively. The common matrix materials present a typical brittle failure (as Figure 25 shows) and the evident occurrence of fiber pullout shows that the matrix-fiber interface bonding is not optimal. The spaces between the fibers are greater than those of EP/clay nano-GFRP as Figure 26 demonstrates. The closer fiber bonding of EP/clay nano-GFRP means that the integral mechanical properties of the EP/clay nano-GFRP are

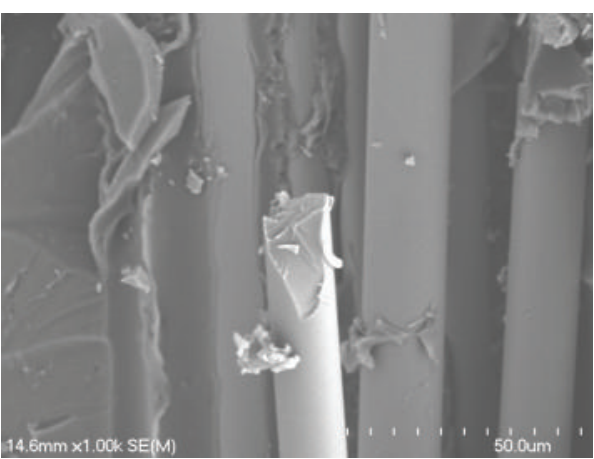

FIGURE 28: The SEM images of longitudinal section of fiber fracture of EP/clay nano-GFRP.

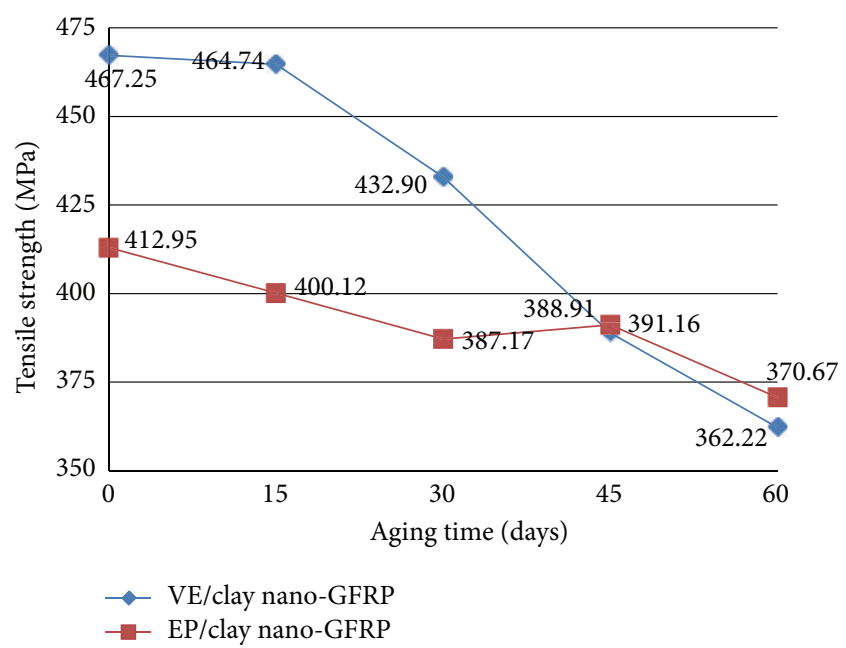

FIgURE 29: Tensile strength of nano-GFRP immersed in water.

superior due to the fact that most of the applied load is not carried by a single fiber but rather by a bunch of fibers.

Figures 27 and 28 show the fracture surface of fiber embedded in EP-GFRP and EP/clay nano-GFRP, respectively. In Figure 27, both the fragments of the matrix materials and the pullout of fibers resulting from failure of the matrix materials indicate the inferior mechanical properties compared with these of EP/clay nano-GFRP. The fracture surface of EP/clay nano-GFRP is smoother and the bonding between matrix and fibers results in more desirable mechanical behavior.

\subsection{Comparison between VE/Clay Nano-GFRP and EP/Clay} Nano-GFRP. Table 2 compares the deterioration in mechanical properties of the two types of nano-GFRP immersed in both water and alkaline solution. The deterioration of EP/clay nano-GFRP is found to be less than that of VE/clay nanoGFRP for immersion in both water and alkaline solution. This indicates that the EP/clay nano-GFRP has a superior ability to resist the permeation of water and chemicals. Although the initial tensile strength of VE/clay nano-GFRP is superior before immersion in water or alkaline solution (as Figures 29 and 30 show), it decays rapidly, and after a certain time the tensile strength is less than that for EP/clay nano-GFRP exposed to the same conditions. 
TABLE 2: Reduction amplitudes of nano-GFRP immersed in water and alkaline solution.

\begin{tabular}{|c|c|c|c|c|}
\hline \multirow{2}{*}{ Aging time (days) } & \multicolumn{2}{|c|}{ Water } & \multicolumn{2}{|c|}{ Alkaline solution } \\
\hline & VE/clay nano-GFRP & EP/clay nano-GFRP & VE/clay nano-GFRP & EP/clay nano-GFRP \\
\hline 15 & $0.54 \%$ & $3.11 \%$ & $11.20 \%$ & $4.22 \%$ \\
\hline 30 & $7.35 \%$ & $6.24 \%$ & $16.23 \%$ & $13.13 \%$ \\
\hline 45 & $16.76 \%$ & $5.28 \%$ & $25.28 \%$ & $28.99 \%$ \\
\hline 60 & $22.48 \%$ & $10.24 \%$ & $47.91 \%$ & $32.02 \%$ \\
\hline
\end{tabular}

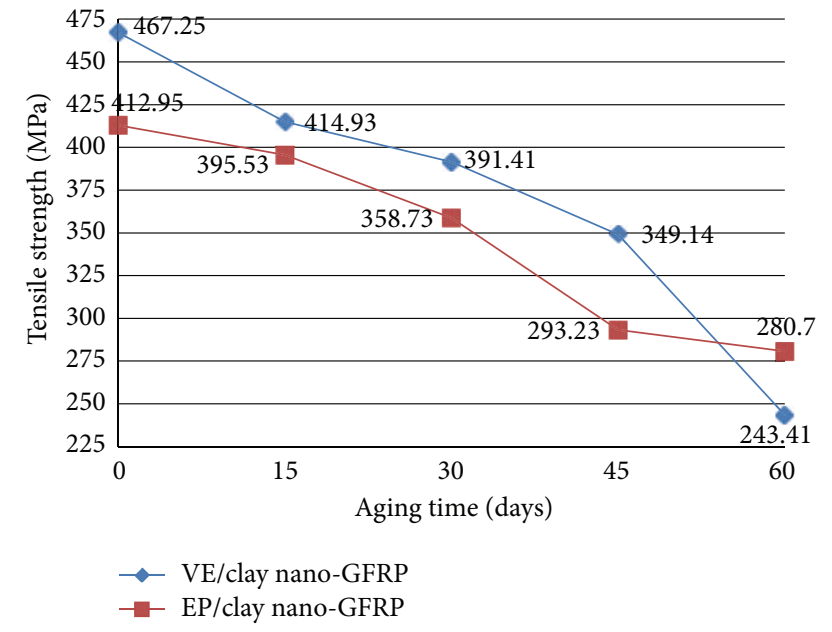

Figure 30: Tensile strength of nano-GFRP immersed in alkaline solution.

Because of the high viscosity of epoxy resin, a number of bubbles become trapped in the EP/clay nanocomposites after shear mixing. The probable reason why the initial tensile strength of VE/clay nano-GFRP is greater is that the vinyl bubbles in the EP/clay nanocomposites compromise the mechanical properties by generating stress concentrations. But the overall properties of epoxy resin are superior to those of vinyl ester resin, so the decay in tensile strength of EP/clay nano-GFRP is less. Furthermore, the effect of adding montmorillonite to improve the durability is more significant for EP/clay nano-GFRP.

\section{Conclusion}

Improvement in the durability of GFRP was achieved by adding montmorillonite composed of neat resin and organoclay nanocomposites, which forms a barrier to resist the permeation of water and chemicals into the matrix. Vinyl ester resin and epoxy resin were used as the matrix materials to prepare the nanocomposites. The dispersion states of montmorillonite in the resin were measured by XRD. Tensile tests were conducted to study the mechanical properties of GFRP. SEM was employed to characterize the degradation of the matrix, glass fibers, and the fiber-matrix interface of GFRP. The following conclusions can be drawn from this study.

(1) The $3.23 \mathrm{~nm}$ interlayer spacing measured by XRD indicates that polymer molecules intercalate into the interlayer space or even that some of the clay becomes exfoliated.

(2) The reductions in the tensile strength of VE-GFRP and VE/clay nano-GFRP immersed in water at $60^{\circ} \mathrm{C}$ were $22.48 \%$ and $21.38 \%$, respectively. The tensile strength of the VE-GFRP and the VE/clay nanoGFRP immersed in alkaline solution was $47.91 \%$ and $57.24 \%$, respectively. The reductions in the tensile strength of EP-GFRP and EP/clay nano-GFRP immersed in water at $60^{\circ} \mathrm{C}$ were $10.24 \%$ and $18.74 \%$, respectively. The reductions in the tensile strength of EP-GFRP and EP/clay nano-GFRP immersed in alkaline solution were $32.02 \%$ and $38.41 \%$, respectively. The decline in the material properties of the VE/clay and EP/clay nano-GFRP composites was smaller than for VE-GFRP over the duration of the accelerated deterioration tests. According to the analysis of the relative influence of water and alkaline ions on the durability of the samples, the barrier formed by the addition of montmorillonite can resist the erosion induced by alkaline ions for up to 45 days. The durability of the nano-GFRP is thus improved by the addition of montmorillonite.

(3) VE/clay nano-GFRP tensile strength decreased by $22.48 \%(47.91 \%)$ after 60 days of immersion in water (alkaline solution), which is greater than the decrease measured for EP/clay nano-GFRP. This leads to the conclusion that EP/clay nano-GFRP has the best durability characteristics of the materials tested in this study. If fabrication techniques for EP/clay nanocomposites can be optimized, the properties of EP/clay nano-GFRP may be improved even further.

\section{Acknowledgments}

The financial support of this study by the Shenzhen Strategic Emerging Industry Development Special Fund (project code JCYJ20120613114340451) and the National Science Fund for Distinguished Young Scholars of China (no. 50925829) are gratefully acknowledged. Technical support from the Shenzhen Durability Center for Civil Engineering and Dr. Hongzhi Cui is much appreciated.

\section{References}

[1] G. Nkurunziza, A. Debaiky, P. Cousin, and B. Benmokrane, "Durability of GFRP bars: a critical review of the literature," 
Progress in Structural Engineering and Materials, vol. 7, no. 4, pp. 194-209, 2005.

[2] H.-G. Zhu, C. K. Y. Leung, J.-K. Kim, and M.-Y. Liu, "Degradation of glass fiber-reinforced plastic composites containing nanoclay in alkaline environment," Journal of Composite Materials, vol. 45, no. 21, pp. 2147-2156, 2011.

[3] Y. Ke, C. Long, and Z. Qi, "Crystallization, properties, and crystal and nanoscale morphology of PET-clay nanocomposites," Journal of Applied Polymer Science, vol. 71, no. 7, pp. 1139-1146, 1999.

[4] T. Uomoto, "Development of new GFRP with high alkali resistivity," in Proceedings of the 4th International Conference on Advanced Composite Materials in Bridges and Structures (ACMBS '04), Canadian Society of Civil Engineering, Alberta, Canada, 2004.

[5] J. G. Teng, FRP Composites in Civil Engineering: Proceedings of the International Conference on FRP Composites in Civil Engineering, Elsevier Science \& Technology Books, 2001.

[6] J. L. Thomason, "The interface region in glass fibre-reinforced epoxy resin composites: 3 . Characterization of fibre surface coatings and the interphase," Composites, vol. 26, no. 7, pp. 487498, 1995.

[7] S. Marouani, L. Curtil, and P. Hamelin, "Ageing of carbon/epoxy and carbon/vinylester composites used in the reinforcement and/or the repair of civil engineering structures," Composites B, vol. 43, no. 4, pp. 2020-2030, 2012.

[8] J.-P. Won, Y.-N. Yoon, B.-T. Hong, T.-J. Choi, and S.-J. Lee, "Durability characteristics of nano-GFRP composite reinforcing bars for concrete structures in moist and alkaline environments," Composite Structures, vol. 94, no. 3, pp. 1236-1242, 2012.

[9] R. Sen, G. Mullins, and T. Salem, "Durability of E-glass/vinylester reinforcement in alkaline solution," ACI Structural Journal, vol. 99, no. 3, pp. 369-375, 2002.

[10] K. P. Chong, "Durability of composite materials and structures," in Proceedings of the 1st International Conference on Durability of Fiber Reinforced Polymer (FRP) Composites for Construction (CDCC '98), pp. 1-12, Quebec, Canada, 1998.

[11] G. Swit, "Durability of stressed E-glass fibre in alkaline medium," in Recent Developments in Durability Analysis of Composite System, pp. 473-476, Balkema, Rotterdam, The Netherlands, 2000.

[12] T. Valter and T. Ralejs, "Durability and service life prediction of GFRP for concrete reinforcement," in FRPRCS-5: Durability of Fibre Reinforced Plastics, vol. 2, pp. 505-513, 2001.

[13] M. Alexandre and P. Dubois, "Polymer-layered silicate nanocomposites: preparation, properties and uses of a new class of materials," Materials Science and Engineering R, vol. 28, no. 1, pp. 1-63, 2000.

[14] ASTM D3039, Standard Test Method for Tensile Properties of Polymer Matrix Composite Materials, 2005. 

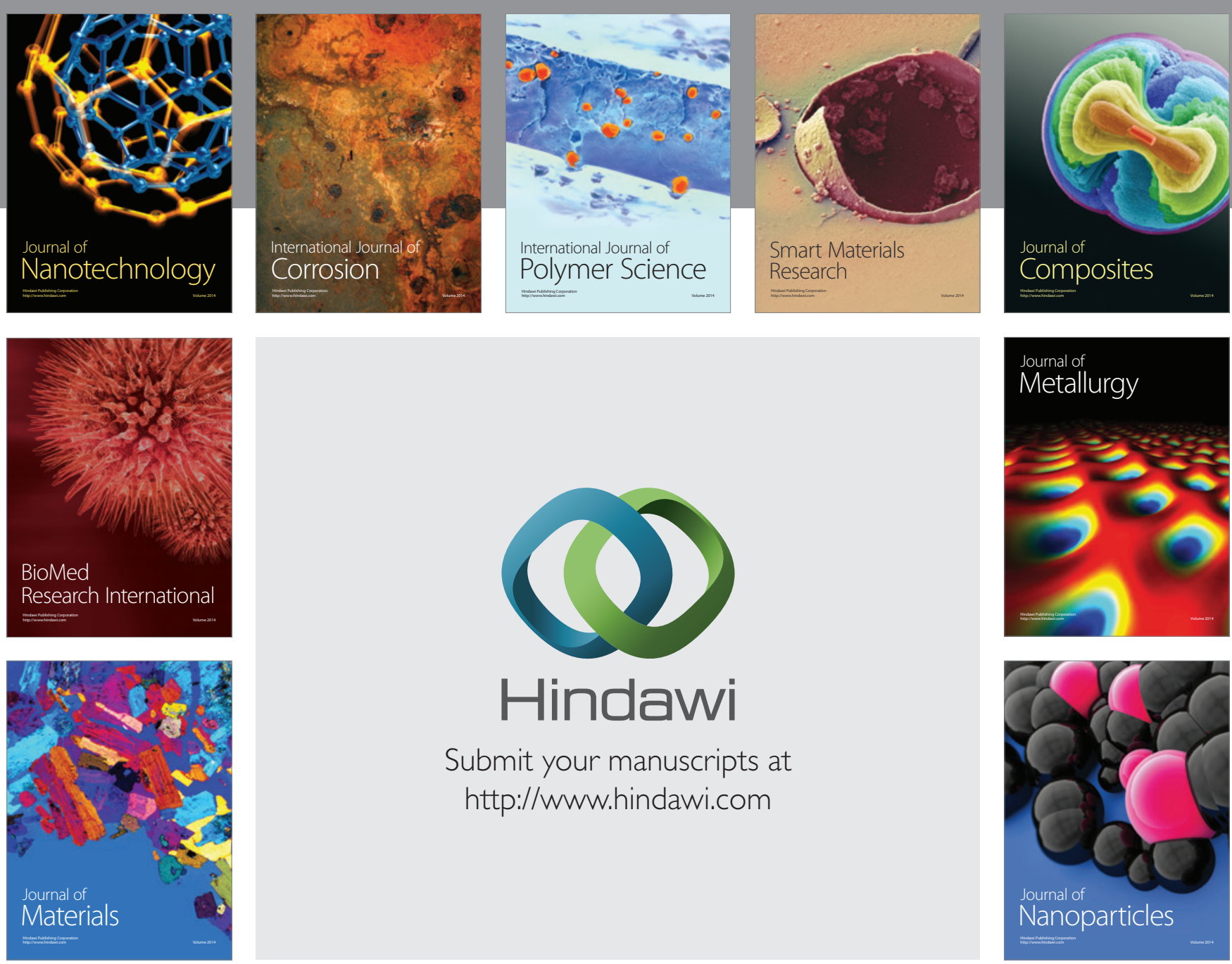

Submit your manuscripts at http://www.hindawi.com
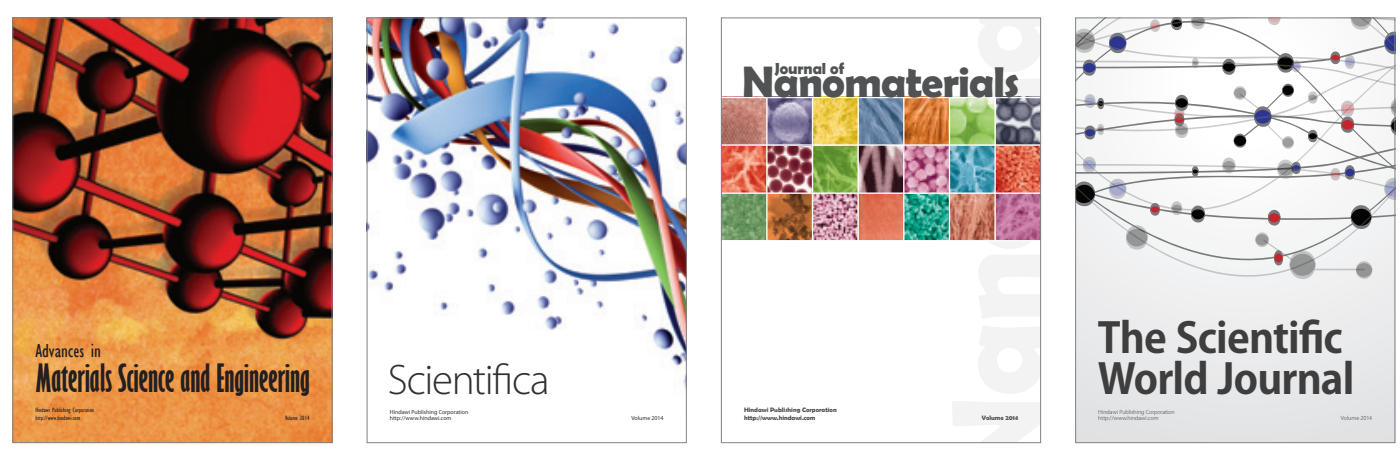

\section{The Scientific World Journal}
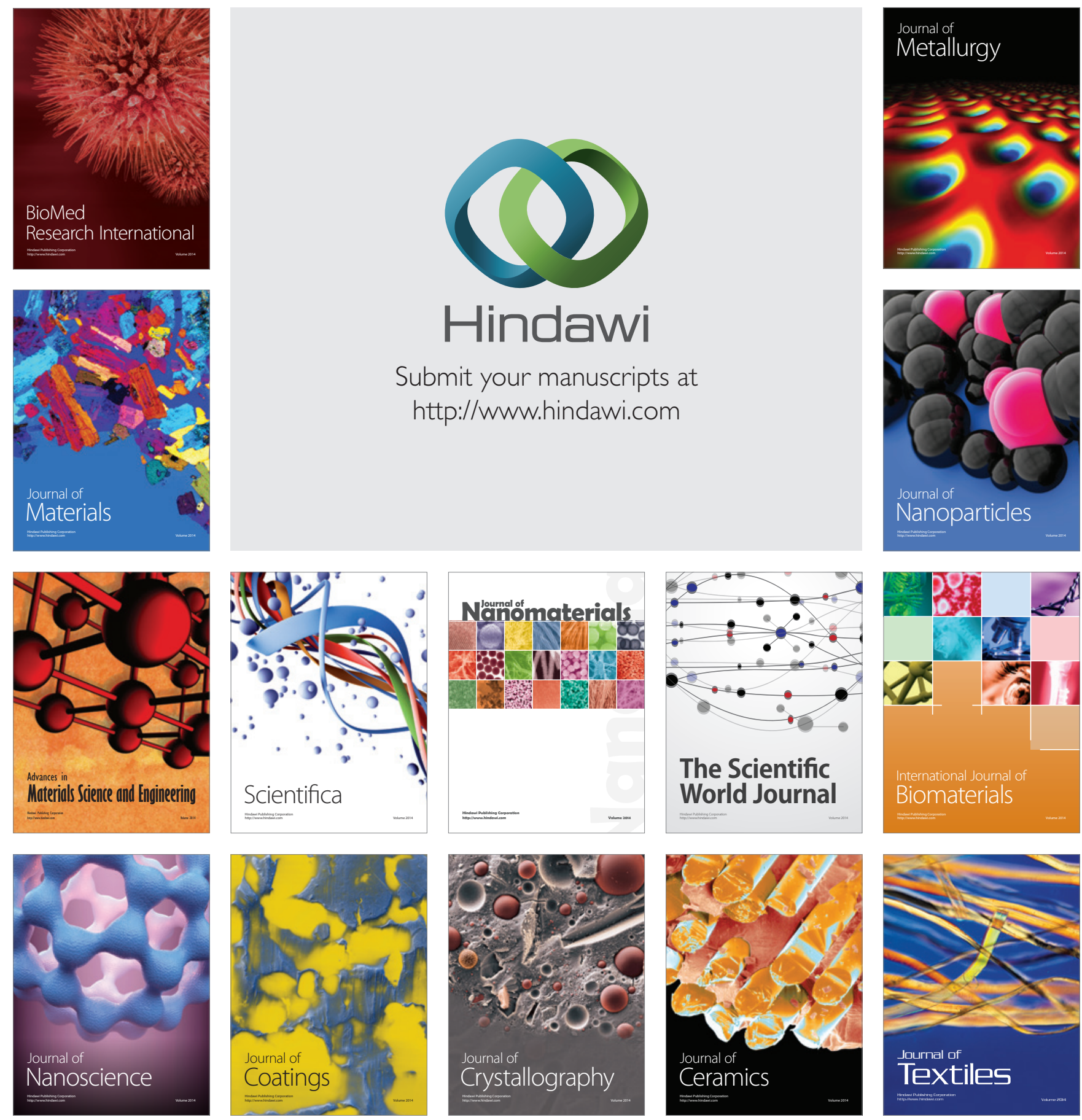